\title{
Academic and Student Perceptions on the Integration of HIV and AIDS education in an Electrical Engineering Curriculum at a South African University of Technology
}

\author{
Luwes, Nicolaas $^{\mathrm{a}}$; Meda, Lawrence ${ }^{\mathrm{a}}$ and Swart, James ${ }^{\mathrm{b}}$ \\ ${ }^{a}$ Department of Electrical, Electronic and Computer Engineering, Central University of \\ Technology, Free State (CUT), South Africa, ${ }^{\mathrm{b}}$ Academic Development \& Support, Central \\ University of Technology, Free State (CUT), South Africa, ${ }^{\mathrm{c} D e p a r t m e n t}$ of Electrical, \\ Electronic and Computer Engineering, Central University of Technology, Free State \\ (CUT), South Africa.
}

\begin{abstract}
South Africa has the largest number of people living with HIV and AIDS in the world. A concerted effort is needed to address this epidemic, lest a socioeconomic crisis may cripple the country. Education may be the most powerful weapon in this regard, with universities playing a critical role in addressing this concern. In 2015, a funding program was initiated by Universities South Africa to facilitate this integration. Subsequently, the Department of Electrical, Electronic and Computer Engineering at a South African University of Technology set out to re-design their curricula to include vital aspects relating to HIV and AIDS. A responsive driven curriculum design was adopted whereby the perceptions and expectations of facilitators and students in this department towards HIV and AIDS education were sought. An online open-ended questionnaire was used to gather both qualitative and quantitative results. This paper presents the initial findings of this study. A key recommendation of this study is to develop a digital online module addressing advanced HIV and AIDS education with special focus on its application in the workplace.
\end{abstract}

Keywords: tertiary education; feedback; online module; perspectives 


\section{Introduction}

HIV and AIDS is currently one of the main causes of death in various countries of the world. Sub-Sahara Africa is the worst affected region where it accounted for $74 \%$ of mortalities due to AIDS related causes in 2013 (UNAIDS, 2014). Whiteside (Whiteside, 2002) states that the estimation peak, or decline of the true death toll, cannot be established until the full waveform of the epidemic has been seen, which might take as long as 20 years. It is also stated that unless there is a concerted effort to address the socio-economic impact of this disease, in particular HIV and AIDS-related poverty, things will get much worse over the coming years and decades.

Although South Africa (SA) does not have the largest percentage of infection, it has the largest number of people living with the disease in the world, being estimated at approximately 5.51 million people (Africa, 2014). HIV and AIDS school education in SA falls under the life orientation curriculum. It starts with basic information at primary school level and is further integrated into secondary school curricula (DoE, 2011), where education focuses primarily on introducing learners to the various diseases and how they may be contracted, highlighting their basic human rights, and helping learners to grasp how they can maintain a relatively healthy lifestyle.

Recently, Universities SA mandated all universities in the country to step up their efforts in responding to this epidemic (HEAIDS, 2010), in a drive to provide on-going and relevant education regarding this disease. However, reports indicate that higher educational institutions in SA are not integrating HIV and AIDS education into their curricula with enough vigour (De Lange, Van Laren, \& Tanga, 2014; Tanga, De Lange, \& Van Laren, 2014). Reason seem to be a perception that students have learnt everything there is to know about the epidemic during their school education (Wilmot \& Wood, 2012). Similar research conducted by Higher Education AIDS (HEAIDS) concluded that universities in SA did not see it reasonable to integrate HIV and AIDS education into their curricula (HEAIDS, 2010).

The following research questions therefore arise: "Are facilitators at a University of Technology in SA favourable towards including HIV and AIDS education in their curricula?" "What type of HIV and AIDS education do students at this university require?" "How may this integration of HIV and AIDS into the engineering curriculum be achieved?" The answer might lie in the declaration that education is the single most powerful weapon against HIV transmission (Sukati, Vilakati, \& Esampally, 2010). Providing this on-going and relevant education may well be achieved by making use of appropriate educational technologies in higher education.

The Department of Electrical, Electronic and Computer Engineering at the Central University of Technology (CUT) in SA set out to re-design their curricula to include HIV and AIDS education by adopting a responsive driven approach. The first step in this 
approach involved obtaining the perceptions and expectations of facilitators and students towards HIV and AIDS education. The purpose of this paper is to present these results and subsequent recommendations. Kosslyn and Rosenberg's (Kosslyn \& Rosenberg, 2001) notion of perception states that one's perception, being either positive or negative, influences one's behaviour which in turn affects beliefs. The importance of student perceptions was discussed as early as 1949 with Tyler who stated that student's views should be seriously considered because they are the receivers of the curriculum (Tyler, 2013). Pinar (Pinar, 2012) stated that a student driven curriculum produces desirable results because of its responsive nature. The paper will firstly discuss a number of current HIV and AIDS educational programmes, followed by the research methodology. Results are presented in corresponding topics so that correlations can be drawn. Conclusions are discussed with possible considerations and proposals for future content development.

\section{HIV and AIDS in higher education}

In 2010, HEAIDS published the findings of a Rapid Assessment Survey as sent to Deputy Vice Chancellors (DVC) and Deans at all Higher Education Institutions (HEI's) of SA (HEAIDS, 2010). DVCs were asked to describe their priority activities with regard to HIV and AIDS education in their institutions. The results of this survey revealed that there is no generic approach for HIV and AIDS education in Universities of Technologies, as well as for traditional universities in SA. Furthermore, those who did indicate a priority activity did so for different faculties. Priorities were are also vague with many focusing primarily on creating awareness of the disease, with no indication of activities in Engineering. 5 of the 17 universities did not even indicate priority activities regarding HIV and AIDS education. Noteworthy is the priority activities for the University of KwaZulu-Natal that aims to provide support for students and staff to be tested and to obtain treatment.

One can state that currently in SA, no generic approach exists for HIV and AIDS education in higher education. It is of concern that the last report on this issue was only documented in 2010. Newer strategies and activities must have been implemented since then to ensure the successful education of students regarding this epidemic. On a more positive note, Universities SA did initiate a funding program in 2015 to further facilitate more and intensive HIV and AIDS educational programmes for higher education in SA. The funding program includes a section on content development which becomes the focus of this paper in terms of determining what specific content electrical engineering students are interested in for such an educational programme. 


\section{Methodology}

A descriptive survey study is used to gather both qualitative and quantitative data. Descriptive studies can provide information about the naturally occurring health status, behavior, attitudes or other characteristics of a particular group, without changing or manipulating any variables. This type of study is ideal to use as it seeks to understand specific people's views (Yin, 2013). Fraenkel and Wallen (Fraenkel, Wallen, \& Hyun, 1993) contend that qualitative and quantitative approaches are not diametrically opposed, but, can complement one another. A qualitative approach was preferred because it enabled participants to freely express their views, while providing rich textual data about a particular phenomenon (Creswell, 2002). A quantitative approach was used to analyse a series of closed ended questionnaires which were drawn from the literature.

Pragmatism was used as a research paradigm for this study, as it is an ideal paradigm for a mixed methods approach (Creswell, 2002). In the mixed methods research community, pragmatism is defined as a deconstructive paradigm that debunks concepts such as truth and reality and focuses instead on what works as the truth regarding the research questions under investigation (McCoy, 2015).

The target population was restricted to all facilitators in the Department of Electrical, Electronic and Computer Engineering at CUT. This negates the need for a sampling technique. However, only students enrolled for Logic Design III, Electrical Engineering II and Digital Signal Processing IV were asked to complete the questionnaire, which forms the data collection instrument. The reason for this was to first pilot the questionnaire in an attempt to resolve any concerns, ambiguity, misinterpretations, difficulties, errors and questions of validity.

Two questionnaires were developed, one for facilitators and one for students. Ethical clearance was requested and received for both questionnaires. Facilitator's and students questionnaire's was loaded onto e-Thuto (learning management system). Of the 22 facilitators in the Department, only 9 voluntarily completed the questionnaire resulting in a response rate of $45 \%$. 17 were males with 3 females, of which 11 were black, 1 was coloured and 8 whites. The student's could access there questionnaire during November 2015. However, only 74 of the 100 attempted the questionnaire, of which 36 successfully completed it. This resulted in a response rate of $36 \%$. The completed questionnaires were received from 28 black students, 4 coloured students and 4 white students. They comprised 24 male and 12 female students with the majority between the ages of 21 and 25 years of age (23 students). Reasons as to why 38 students did not successfully complete the online questionnaire were also sought in an effort to improve the survey. Results of this process are not presented in this paper. 
The questionnaires were designed to consist of five specific sections. The first section measured participant perceptions on integrating HIV and AIDS education into higher education. The second section targeted student prior knowledge of HIV and AIDS education in order to verify what content was covered at school level. The third section focused on HIV and AIDS educational content specifically aimed for the workplace. The fourth section sought to obtain perceptions of electrical engineering students with regard to what other specific content they would prefer to see in the HIV and AIDS educational programme. The fifth section obtained participant responses with regard to preferred modes of delivery of the educational programme.

\section{Results and discussion}

As stated, the purpose of this paper is to obtain facilitator and student perceptions on the integration of HIV and AIDS education into an electrical engineering curricula. These results could lead to an effective responsive curriculum design.

\subsection{Perceptions on HIV and AIDS education}

It is important to determine perceptions on HIV and AIDS education.

Results show that $50 \%$ of the facilitators felt that students have been taught enough about HIV and AIDS in primary and secondary school, and hence it should not be integrated into the university curriculum. Contrary to this, only $10.7 \%$ of the students felt they have enough knowledge where $67.9 \%$ of the students stated that they would like to learn more about this disease in order to protect themselves.

Only $37.5 \%$ of the facilitators felt that HIV and AIDS is a problem affecting everyone and that every facilitator should teach students about this disease wherever possible. One can conclude that $67.9 \%$ of the students want to learn more in order to make a success of their future career, but only $37.5 \%$ of the facilitators would have a positive attitude towards such an educational programme. So, great care should be taken when designing and implementing an HIV and AIDS educational programme for higher education, as all facilitators need to buy into the concept if it is to be successful.

\subsection{HIV and AIDS education prior knowledge}

On average, $85 \%$ of student responses to questions on HIV and AIDS education as taught in primary and secondary school were correct. $50 \%$ of facilitators indicated their confidence in the HIV and AIDS educational programme provided in primary and secondary school by 
stating that it was sufficient to equip students with the necessary knowledge. These facilitators therefore felt that there is no need to integrate another HIV and AIDS educational programme into the university curriculum. However, students want to learn more, which leads to questions about what content for the workplace and content in general would students want to know.

\subsection{What students want to learn about HIV and AIDS education}

It is important to determine what other type of content would be desired by electrical engineering students in a new HIV and AIDS educational program at university level.

15.8 percent of the students indicated that they would welcome more general knowledge on the subject, thereby suggesting more awareness is required. $26 \%$ of the students indicated that voluntary counseling and testing for HIV and AIDS should be included in the program. Workplace related concerns for HIV and AIDS infected people were further requested by $21.1 \%$ of the students. This equates well with the previous subsection in this regard. However, the most requested information in this regard relates to various treatment options and complications of these treatments (31.6\% requested this). Some of the student comments included "How are people with HIV and AIDS treated at the work environment", "How does it correlate with CD4 count and how are ARVs used", "What are the different laboratory tests that are performed" and "How can I treat and care for someone having it". These comments suggest that some students are really concerned about how this disease is diagnosed and treated. Thoughts from the facilitators, with regard to content, were concentrated on preparing students on how to act and behave when faced with a situation of working with an HIV positive colleague.

\subsection{Perceptions of mode of delivery}

A responsive curriculum design would seek participant feedback on different modes of delivery of the required content. Two main proposals surfaced from the facilitator and student questionnaires. Firstly, $75 \%$ of the students indicated that they would prefer the introduction of a compulsory module which should be taught by an HIV and AIDS specialist. This module should feature across all levels of education, which each subsequent level building on previous knowledge. One student stated "I personally think there should be a subject such as Life Skills (it's just an example) where all these topics can be addressed, even if it is once every month for all faculties. Every session can be focused on a different topic concerning the challenges we are facing in this regard". 3 facilitators commented as follows "HIV and AIDS should be taught to students in generic modules such as Life Skills, not in engineering education", "Our students barely have time to learn 
about HIV and AIDS. They struggle with our engineering subjects in such a short period of time" and "The syllabus is already full and time is limited, so at this stage there is no way that I can bring this into my syllabus." These comments suggest, that while students want a separate module dedicated to HIV and AIDS education, there seems to be no place for it in the already packed engineering curriculum. This gives support to the second proposal, being a digital approach.

$19 \%$ of students indicated that the content for the HIV and AIDS educational programme may be shared using e-Thuto, social media, mobile phones and the Internet. Facilitators further indicated that "Digital literacy is important". Study guides and pamphlets may also be incorporated into this digital approach. This would afford students the opportunity to review the information at their own time and leisure. It would also provide those students who really want to learn more with the needed information to make an informed decision when working with someone infected with HIV and AIDS.

\section{Conclusion}

The purpose of this paper was to present facilitator and student perceptions of integrating HIV and AIDS education into an electrical engineering curriculum. A responsive curriculum design is thus envisioned. Responses from facilitators indicated that such an educational programme is a waste of time, as students already know enough about this topic as they were taught about it during primary and secondary education. On the other hand, students felt they do not know enough about this topic, especially with regard to HIV and AIDS in the electrical engineering workplace. What chemicals and electronic equipment would be problematic to handle by infected personnel? What treatment (both emotionally and physically) should be provided to someone in the workplace that has been infected? Answers to these and other questions may be provided by considering a digital approach. Institutional learning management systems may be used to disseminate this specific information to those students who want to learn more. This will negate the need for a specialised module to be incorporated into a fully packed electrical engineering curriculum.

Although this descriptive survey study was only limited to 9 facilitators and 36 students, it provided sufficient reason to investigate an HIV and AIDS educational program centered on workplace content. It has also been possible to address the concerns identified in the online questionnaire, thereby making it now possible to release the questionnaire to a greater pool of students. Results of the refining process of the questionnaire and future responses are planned for another paper. The initial results of this study may now already be used, in collaboration with an occupational health specialist (specialising in HIV and AIDS) to develop a relevant HIV and AIDS educational program for CUT. Using such educational programs in an effective way may just be the most powerful weapon that 
currently exists to continue the fight against HIV and AIDS, which still remains one of the leading causes of death in Sub-Sahara Africa.

\section{References}

Africa, S. S. (2014). Mid-year population estimates. Statistics South Africa Retrieved from http://www.statssa.gov.za/publications/P0302/P03022014.pdf

Creswell, J. W. (2002). Educational research: Planning, conducting, and evaluating quantitative: Prentice Hall.

DBE, R. (2011). Curriculum and Assessment Policy Statement GRADES 10-12 Life Orientation. Department of Basic Education Retrieved from http://www.education.gov.za.

De Lange, N., Van Laren, L., \& Tanga, P. (2014). 'Close to the bone'?: catalysts for integrating HIV and AIDS into the academic curriculum. South African Journal of Higher Education, 28(4), 1173-1193.

DoE. (2011). Curriculum and Assessment Policy Statement: Grades 7-9. Pretoria: Retrieved from http://www.education.gov.za

Fraenkel, J. R., Wallen, N. E., \& Hyun, H. H. (1993). How to design and evaluate research in education (Vol. 7): McGraw-Hill New York.

HEAIDS. (2010). Creating space for HIV and AIDS in the curriculum - A Rapid Assessment of curricular responses in South African Higher Education Institution. Pretoria: Higher Education South Africa Retrieved from http://heaids.org.za/site/assets/files/1248/4982 hesa_creating_space for_hiv and aids in_the_curriculum.pdf.

Kosslyn, S. M., \& Rosenberg, R. S. (2001). Psychology: The brain, the person, the world (Vol. 1): Prentice Hall.

McCoy, D. L. (2015). MIXED METHODS RESEARCH. Research in the College Context: Approaches and Methods, 24.

Pinar, W. F. (2012). What is curriculum theory? : Routledge.

Sukati, C., Vilakati, N., \& Esampally, C. (2010). HIV/AIDS education: what works for Swaziland University students? Educational Research, 52(1), 101-113.

Tanga, P. T., De Lange, N., \& Van Laren, L. (2014). 'Listening with our eyes': collaboration and HIV and AIDS curriculum integration in South African higher education. TD: The Journal for Transdisciplinary Research in Southern Africa, 10(1), 169-186.

Tyler, R. W. (2013). Basic principles of curriculum and instruction: University of Chicago press.

UNAIDS. (2014). The Gap Report. Retrieved from http://www.unaids.org/en/media/unaids/contentassets/documents/unaidspublication/201 4/UNAIDS_Gap_report_en.pdf.

Whiteside, A. (2002). Poverty and HIV/AIDS in Africa. Third world quarterly, 23(2), 313332. 
Wilmot, D., \& Wood, L. (2012). In search of an enabling pedagogy for HIV and AIDS education in initial teacher education. South African Journal of Higher Education, 26(5), 1112-1130.

Yin, R. K. (2013). Case study research: Design and methods: Sage publications. 